\title{
Rationale and Design of: A Randomized tRial of Expedited transfer to a cardiac arrest center for non-ST elevation out-of-hospital cardiac arrest: The ARREST randomized controlled trial
}

Tiffany Patterson ${ }^{1}$ PhD, Alexander Perkins² MSc, Gavin D Perkins ${ }^{3}$ MD, Tim Clayton² MSc, Richard Evans $^{2}$ BA, Hanna Nguyen 1 , Karen Wilson ${ }^{1}$ MSc, Mark Whitbread ${ }^{4}$ MSc, Johanna Hughes ${ }^{4}$, Rachael T Fothergill ${ }^{3,4} \mathrm{PhD}$, Joanne Nevett ${ }^{4} \mathrm{MSc}$, Iris Mosweu ${ }^{5} \mathrm{MSc}$, Paul McCrone ${ }^{5} \mathrm{PhD}$, Miles Dalby ${ }^{6} \mathrm{MD}$, Roby Rakhit ${ }^{7}$ MD, Philip MacCarthy ${ }^{8}$ MD, Divaka Perera ${ }^{1}$ MD, Jerry P Nolan ${ }^{9}$ MB ChB, Simon R Redwood ${ }^{1}$ MD

1. Cardiovascular Division, The Rayne Institute BHF Centre of Research Excellence, King's College London, St. Thomas' Hospital, London, UK

2. London School of Hygiene and Tropical Medicine Clinical Trials Unit, London, UK

3. Warwick Clinical Trials Unit and Heart of England NHS Foundation Trust, Warwick Medical School, University of Warwick, Coventry, UK

4. Medical Directorate, London Ambulance Service, London, UK

5. King's Health Economics, Institute of Psychiatry, Psychology \& Neuroscience, King's College London, UK

6. Department of Cardiology, Royal Brompton and Harefield NHS Foundation Trust, Middlesex, UK

7. Department of Cardiology, Royal Free NHS Foundation Trust, London, UK

8. Department of Cardiology, King's College Hospital NHS Foundation Trust, London, UK

9. School of Clinical Sciences, University of Bristol and Department of Anaesthesia, Royal United Hospital, Bath, UK

Short Title: ARREST Randomized Controlled Trial

Corresponding Author: Simon R Redwood, Professor of Interventional Cardiology, Cardiovascular Department, Kings College London, St Thomas' Hospital, London SE1 7EH

Email: simon.redwood@gstt.nhs.uk Tel: +44 (0) 2071881083

Total Word Count: 4711 (inc. abstract and references)

Disclosure: The authors have no disclosures or conflicts of interest to share.

Keywords: Out-of-hospital Cardiac Arrest, Cardiac Arrest Center, Coronary Angiography.

Acknowledgements: The Pan-London Acute Coronary Syndrome Advisory Group; Advanced Paramedic Practitioners, London Ambulance Service; London School of Hygiene and Tropical Medicine Clinical Trials Unit. 


\begin{abstract}
Background

Out-of-hospital cardiac arrest (OHCA) is a global public health issue. There is wide variation in both regional and inter-hospital survival rates from $\mathrm{OHCA}$ and overall survival remains poor at $7 \%$. Regionalization of care into cardiac arrest centers (CAC) improves outcomes following cardiac arrest from ST elevation myocardial infarction (STEMI) through concentration of services and greater provider experience. The International Liaison Committee on Resuscitation (ILCOR) recommends delivery of all post-arrest patients of to a CAC, but that randomized controlled trials are necessary in patients without ST elevation (STE).
\end{abstract}

\title{
Methods/Design
}

Following completion of a pilot randomized trial to assess safety and feasibility of conducting a largescale randomized controlled trial in patients following OHCA of presumed cardiac cause without STE, we present the rationale and design of A Randomized tRial of Expedited transfer to a cardiac arrest center for non-ST elevation OHCA (ARREST). In total 860 patients will be enrolled and randomized (1:1) to expedited transfer to CAC (24/7 access to interventional cardiology facilities, cooling and goaldirected therapies) or to the current standard of care, which comprises delivery to the nearest emergency department. Primary outcome is 30-day all-cause mortality and secondary outcomes are 30 day and 3-month neurological status and 3, 6 and 12-month mortality. Patients will be followed up for one year after enrolment.

\section{Conclusion}

Post-arrest care is time-critical, requires a multi-disciplinary approach and may be more optimally delivered in centers with greater provider experience. This trial would help to demonstrate if regionalization of post-arrest care to CACs reduces mortality in patients without STE, which could dramatically reshape emergency care provision. 


\section{Introduction}

Out-of-hospital cardiac arrest (OHCA) is a global public health issue. Each year there are 28,000 emergency medical services (EMS)-treated OHCA in England and approximately 330,000 EMSattended $\mathrm{OHCA}$ in the United States.,2 There is wide variation in both regional and inter-hospital survival rates from OHCA and overall survival remains poor, at $7 \% .^{3}$ The adoption of systematic approaches to post-resuscitation care may improve long-term survival from OHCA. ${ }^{4,5}$ Regionalization of care into specialist centers has played a vital role in the management of time-critical illnesses through concentration of services and greater provider experience. ${ }^{6-13}$ Post-resuscitation care in hospitals with the facilities to deliver targeted temperature management and treatment of the underlying cause through coronary reperfusion is thought to further improve this survival in patients. ${ }^{14}$ The International Liaison Committee on Resuscitation (ILCOR) suggests transport of all post-arrest patients to a cardiac arrest center (CAC). It is difficult to conclude which of the components of post-arrest care is essential, given the observational nature of studies. In addition to volume and quality of care delivery, it is of increasing opinion that CACs should provide $24 / 7$ access to interventional cardiology facilities, targeted temperature management, diagnostic imaging capability and standardized neuroprognostication (Table 1). ${ }^{15-18}$ Coronary artery disease is responsible for $>70 \%$ of $\mathrm{OHCA}$, with an acute occlusion demonstrated in $50 \%$ of consecutive patients taken immediately to coronary angiography. ${ }^{19}$ There is expert consensus that early reperfusion therapy in ST-elevation (STE) reduces mortality. ${ }^{20,21}$ Patients without STE however are a heterogeneous group, with an emphasis placed on prior rule out of noncoronary causes. ${ }^{21}$ Due to the lack of randomized data, there has been variable uptake of an early reperfusion strategy amongst the interventional cardiology community. Last year, in London, of the 2393 patients with OHCA and ROSC sustained to hospital, approximately two thirds were delivered to a nonCAC $(1520 / 2393 ; 63.5 \%)$. Of these patients we estimate that between 2 and $4 \%$ were transferred to a CAC following index admission to a non-CAC (Table 2). ILCOR states that randomized trials are therefore essential in this population to determine if timely delivery to a CAC improves survival. ${ }^{22}$ However, the coordination of this is complex and close interaction is necessary between centers and ambulance services and internally between the emergency department, cardiologists and the critical care team. There is an urgent need for randomized control data examining the benefits of early delivery 
of post-cardiac arrest care in specialist centers, specifically in the absence of STE. Post-arrest care is time-critical, requires a multi-disciplinary approach and may be more optimally delivered in centers with greater provider experience. Following completion of a pilot randomized trial to assess safety and feasibility of conducting a large-scale randomized controlled trial in patients without STE, we present the rational and design of A Randomized tRial of Expedited transfer to a cardiac arrest center for non-ST elevation OHCA (ARREST). ${ }^{23}$

\section{Specialty Services and interventions}

$\begin{array}{ll}\text { General } & \text { Standardized post-resuscitation protocol } \\ \text { Critical Care } & \text { Airway management and ventilatory support } \\ & \text { Hemodynamic and renal support } \\ & \text { Acid-base, electrolyte and glucose control } \\ & \text { Targeted temperature management } \\ \text { Cardiothoracic } & \text { Echocardiography } \\ & \text { Immediate coronary angiography and revascularization strategies* } \\ & \text { Mechanical circulatory support } \\ & \text { Electrophysiology and heart failure specialist input } \pm \text { device insertion } \\ \text { Radiology } & \text { 24 hour imaging and interpretation including computed tomography to rule in/out respiratory or neurological causes } \\ \text { Neurology } & \text { Seizure control } \\ & \text { Standardized multimodality neuroprognostication (including neurophysiology testing) } \\ & \text { Physiotherapy and referral to neurorehabilitation services }\end{array}$

Table 1. Important components of a cardiac arrest center providing specialist services and interventions. *revascularization strategies can include percutaneous coronary intervention and coronary artery bypass grafting. 


\begin{tabular}{|l|l|l|}
\hline Hospital & \multicolumn{2}{|l|}{ Number and proportion of patients } \\
\hline Non-Cardiac Arrest Center & 1520 & $63.5 \%$ \\
\hline Cardiac Arrest Center & 873 & $36.5 \%$ \\
\hline Total & 2393 & $100 \%$ \\
\hline
\end{tabular}

Table 2. Destination hospital: CAC versus non-CAC.

This table demonstrates data from 2016-2017 with respect to the destination hospital (CAC versus nonCAC) of patients who would meet current criteria for inclusion the ARREST trial (no-ST elevation, adult cardiac arrest, return of spontaneous circulation). Where $\mathrm{n}$ is the number of patients with the desired characteristic and $\mathrm{N}$ is the total number, the proportion of patients is presented as a \%). It can be seen from this table that of the patients that fulfil current inclusion criteria for the trial, approximately two thirds were delivered to a non-CAC. Of these patients we estimate from the data we have extracted that thereafter, roughly 2 to $4 \%$ are transferred to a CAC. As this data was not collected prospectively this is the best estimate that can be provided based on the assumption that patients were not transferred after their index admission to a non-CAC if (i) patient death was recorded at $<24$ hours and (ii) if the source of survival data was the non-CAC (if the patient was transferred to a CAC the survival data would have been provided by the $\mathrm{CAC}$ ).

\section{Methods}

\section{Trial Design}

ARREST is a multi-center randomized controlled trial being conducted in 30 hospitals in London, United Kingdom. Of these, 7 hospitals provide $24 / 7$ access to interventional cardiology with specialist intensive care facilities (hereafter referred to as CAC, Table 1) and 27 hospitals have emergency departments (Figure 1). The aim is to determine the best post-resuscitation care pathway for patients with arrest of presumed cardiac cause but without STE on the post-resuscitation electrocardiogram (ECG). We propose that changes to emergency management comprising expedited delivery to a CAC with organized post-cardiac arrest care including immediate access to reperfusion therapy (intervention arm) will reduce mortality in patients without STE. We propose minimum criteria for a cardiac arrest center in Table 1. The intervention arm will be compared to the current standard of care (control arm), which 
comprises protracted pre-hospital management of the patient without definitive care plan and delivery to geographically closest emergency department, which could potentially delay both transfer times to hospital and appropriate post-resuscitation care delivery. Patients will be followed up for one year. The trial will conform to the declaration of Helsinki, and in accordance with the Good Clinical Practice guidelines. Due to the emergency nature of the trial and the immediacy of the intervention, the need for prior informed consent has been waived. ${ }^{24}$ If the patient regains capacity following the cardiac arrest, informed consent should be gathered once the initial emergency has passed. ${ }^{25,26}$ The trial was granted ethical approval by the National Research Ethics Committee (REC 13/LO/1508) in January 2014. The trial is sponsored by King's College London, UK and has received charitable funding for the entire trial from the British Heart Foundation CS/16/3/32615. The authors are solely responsible for the design and conduct of this study; all study analyses, the drafting and editing of the paper and its final contents. The trial is registered with International Standard Randomized Controlled Trials www.ISRCTN.com (ISRCTN 96585404). No extramural funding was used to support this work. The authors are solely responsible for the design and conduct of this study; all study analyses, the drafting and editing of the paper and its final contents.

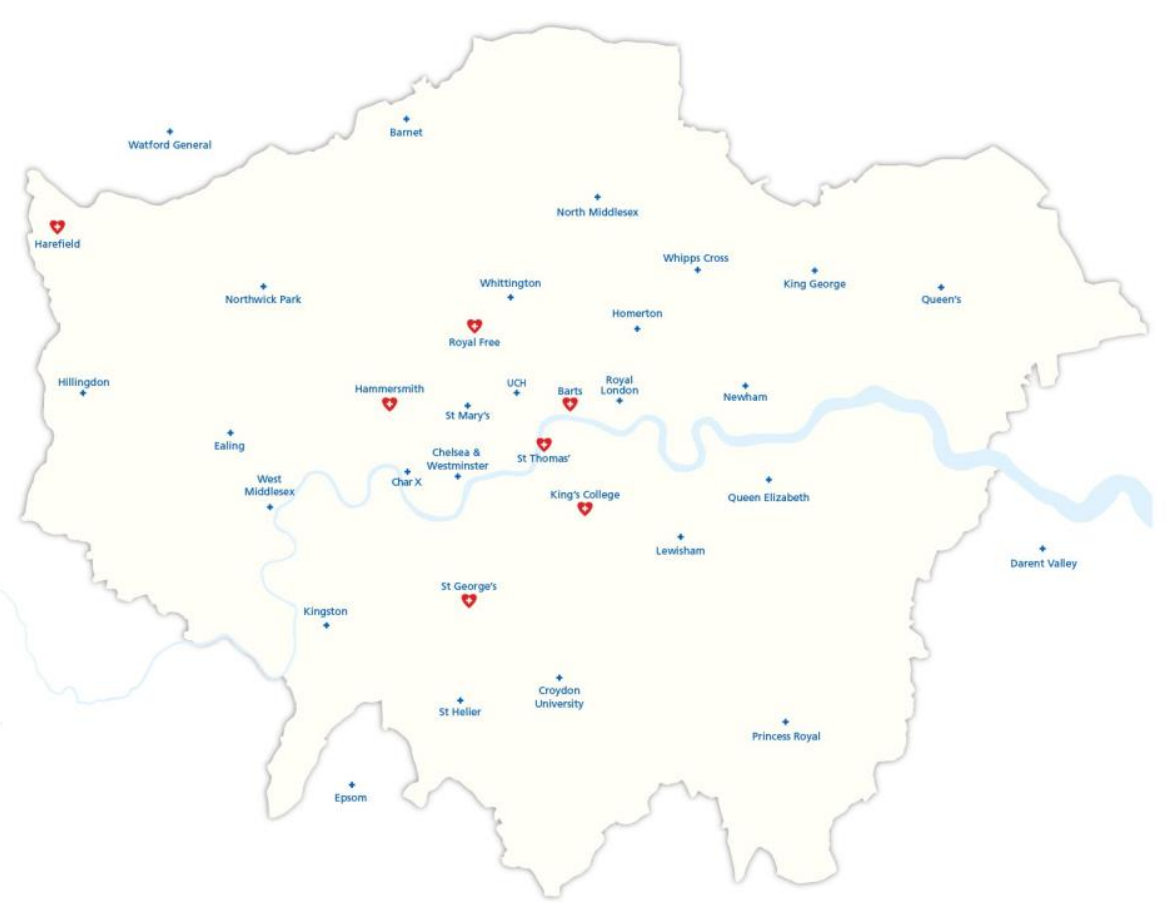




\section{Figure 1. ARREST Trial receiving hospitals}

Map of London demonstrating the receiving hospitals in the ARREST trial, there are 3 participating hospitals in total (correct as of June 2018), 7 of these are CAC (3 CAC do not have EDs). 28 hospitals have emergency departments including 4 CACs. CACs are denoted on the map as a red heart. Abbreviations: Char X Charing Cross Hospital, UCH University College London Hospital

\section{Primary research question}

A post-resuscitation care pathway comprising pre-hospital triage and immediate strategic delivery of the post-cardiac arrest patient of presumed cardiac cause (Table 3) without STE to dedicated CAC, with specialist cardiac resuscitation facilities and access to rapid evaluation and treatment including reperfusion will reduce all-cause mortality at 30 days.

Inclusion

Exclusion

Criteria for ST-elevation myocardial infarction (STEMI) on 12-Lead electrocardiogram

Out-of-hospital cardiac arrest Do Not Attempt Resuscitation (DNAR) Order

\section{Table 3. Inclusion/exclusion criteria.}

Participants must have fulfil all of the inclusion criteria. Patients will be excluded if they meet any of the exclusion criteria. "Cardiac arrest after care pathway set and patient en route" refers to patients who did not present with a cardiac arrest in whom a diagnosis has been made pre-hospital by the paramedic staff and a decision has been made with regard to definitive treatment. If such patients arrest en-route to hospital, they will not be considered eligible for the trial as this may compromise clinical care delivery.

\section{Secondary research questions}


These are as follows: 1) Neurological status at discharge and 3 months and 2) All-cause mortality at 3 ,

6, 12 months. Patients are therefore followed up at 30 days, 3,6 and 12 months, see Figure 2.

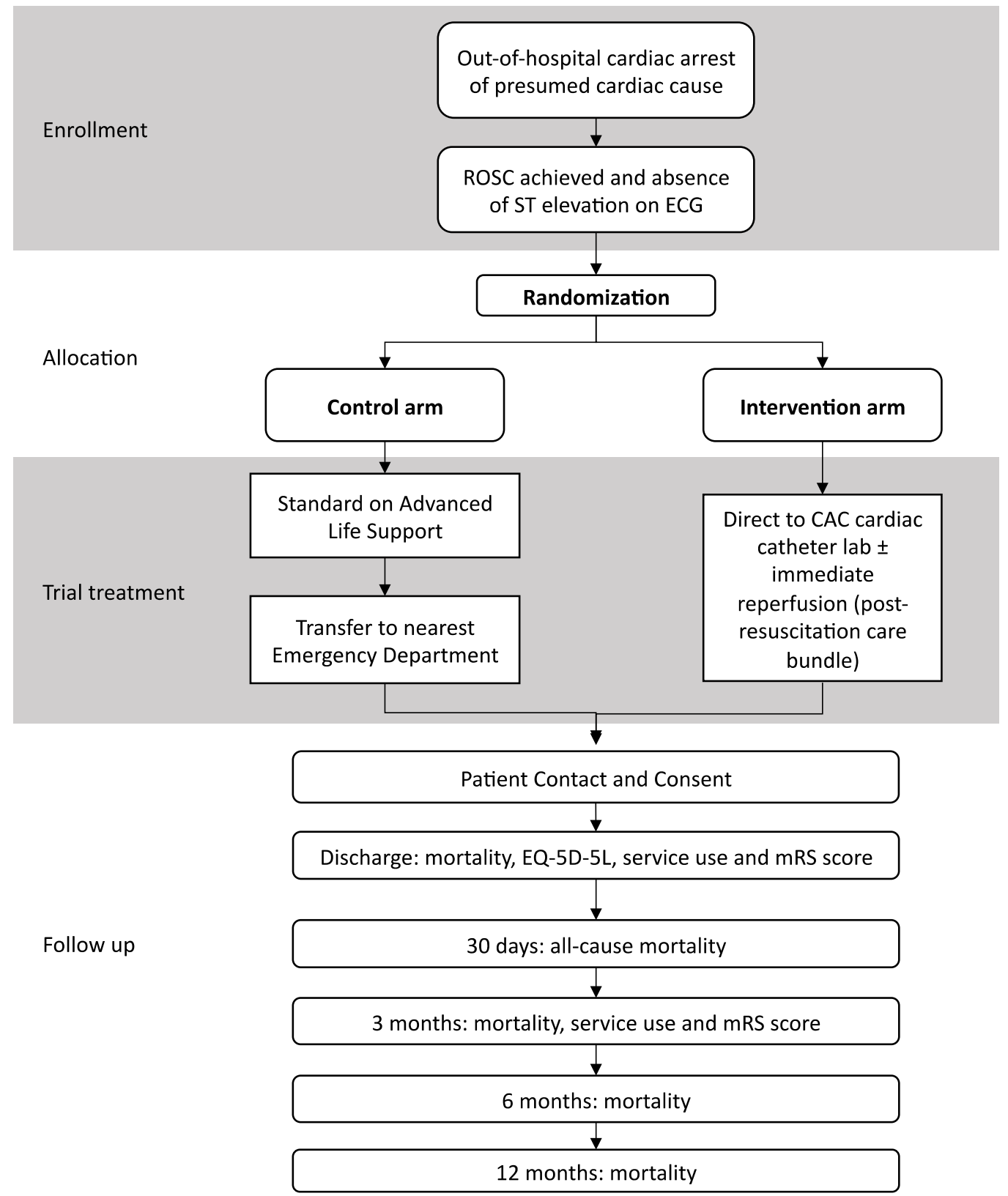

Figure 2 Trial flow diagram

\section{Study Participants}

Patients with confirmed cardiac arrest of presumed cardiac cause will be assessed for eligibility by the attending London Ambulance Service (LAS) paramedic. Inclusion and exclusion criteria are provided in

Table 3. Due to the emergency context of the research, identification cannot be performed in advance. 
Patients who re-arrest after they have been randomized into the trial will not be excluded and will be conveyed to an emergency department (ED) or CAC as indicated by their treatment allocation. If the patient re-arrests on scene and there is recognition of life extinct by the attending paramedic after randomization, the patient will not be transferred to an ED or CAC. The patient will remain in the trial and patient data will be collected. The trial opened to enrollment in January 2018, and the first patient was randomized on February 2, 2018 with recruitment of all patients planned by end of September 2020. Follow-up of all patients is expected by September 2021 (Figure 3) and reporting of results is expected by the end of April 2022.

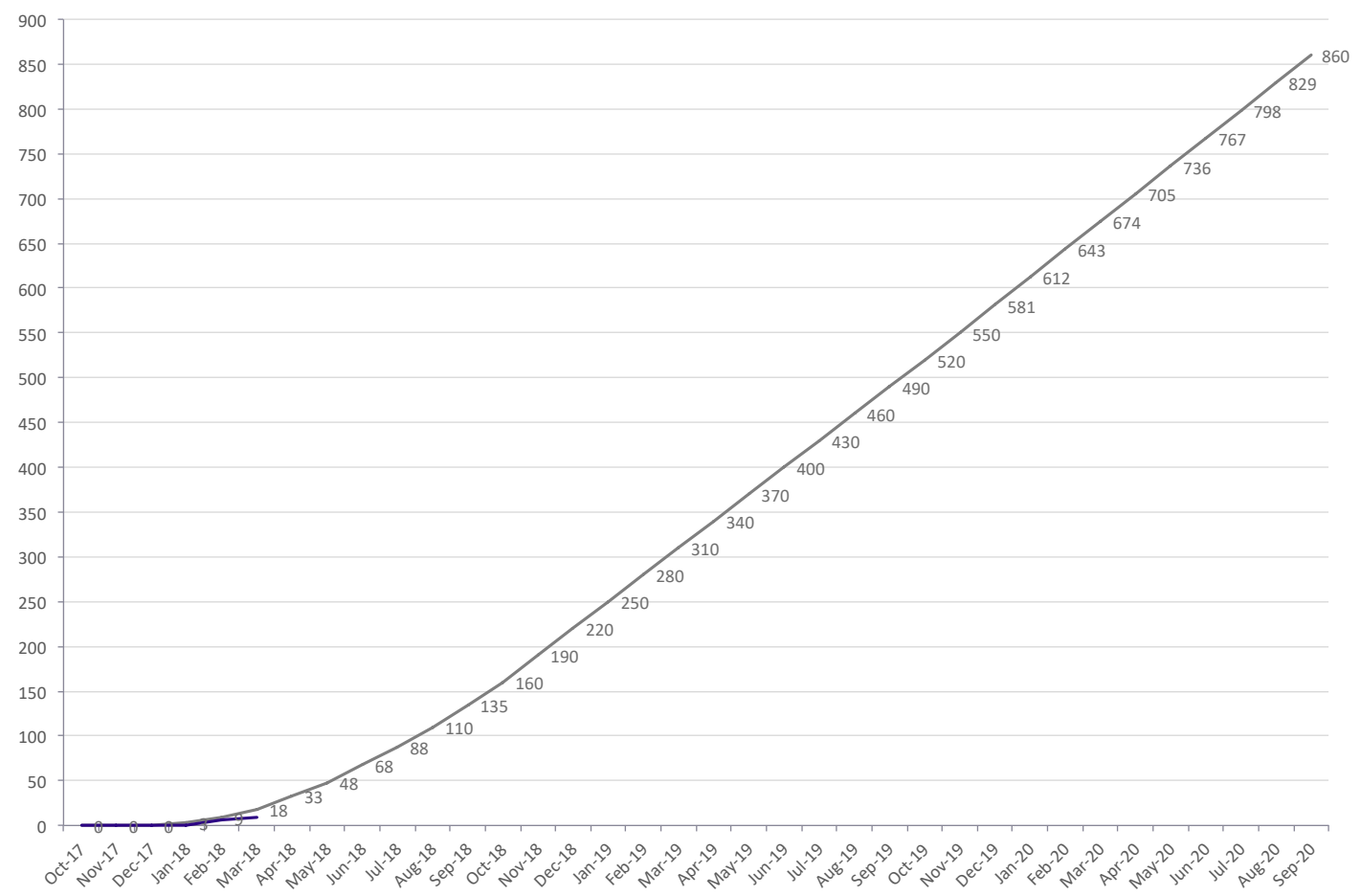

Figure 3. Enrollment graph for ARREST trial

Projected enrollment is depicted as a gray line and actual enrolment is depicted as a purple line. The trial opened to recruitment in January 2018 and the first patient was enrolled in February 2018.

\section{Randomization}

Designated LAS staff at the Advanced Paramedic Practitioner (APP) dispatch desk will randomize patients into the intervention arm or control arm (current standard of care and delivery to the nearest ED where possible) using the following procedure: LAS paramedics attending a suspected OHCA of presumed cardiac cause will assess the patient for eligibility (Table 3). Once eligibility is confirmed, the 
on-site paramedic will contact the APP desk to randomize the patient. The APP desk staff will access the online randomization website (www.sealedenvelope.com), enter the required details, and generate a study ID and treatment allocation. Patients will be randomized either to an expedited transfer to a CAC or to receive standard of care with delivery to the nearest ED where possible. The APP desk will inform the on-site paramedic which group the patient has been randomized to, and the on-site paramedic will proceed as appropriate. The APP desk will provide the necessary information to the Clinical Audit and Research Unit at LAS for them to track the patient report form to obtain clinical data. Due to the radical difference between the interventions in the two study arms, the study cannot be blinded.

\section{Trial Treatments}

Intervention arm

The intervention arm consists of activation of the pre-hospital triaging system currently in place for postarrest STEMI patients. This involves pre-alert of the CAC and strategic delivery of the patient to the cardiac catheter laboratory ( 24 hours a day, 7 days a week) with a view to immediate coronary angiography+/- $\mathrm{PCl}$. The final decision to perform $\mathrm{CA}+/-\mathrm{PCl}$ remains with the Interventional cardiologist responsible for the patient. Patients will receive definitive post-resuscitation care: intubation and ventilation, targeted temperature management, and goal-directed therapies where necessary, including evaluation and identification of underlying cause of arrest with access to immediate reperfusion if necessary as per current guidelines. Neuro-prognostication will occur no earlier than 72 hours postcardiac arrest to prevent premature withdrawal of life-sustaining treatment. Transfer times estimated from the 40-patient pilot are anticipated to be 100 minutes (median; IQR 75 to 113) from time of arrest to the designated center.

\section{Control arm}

The control arm comprises the current standard of pre-hospital advanced life support care management for patients with return of spontaneous circulation (ROSC) following cardiac arrest of suspected cardiac etiology. If the patient survives, they will be conveyed to the geographically closest emergency 
department. Management thereafter will be as per standard hospital protocols however as in the intervention arm, delayed neuro-prognostication is recommended in trial patients.

\section{Crossover}

The likelihood of crossover is anticipated to be low in patients with ROSC in the absence of STE on the ECG. If a clinical decision is made either by the paramedic staff or the in-hospital care team that the patient in the control arm (current standard of care and delivery to the nearest ED) should receive urgent coronary angiography, this will not be considered crossover. Extensive paramedic training has been provided to prevent inappropriate crossover, however if this does happen the patient will remain in the trial (in the arm they were randomly assigned to) as part of the intention to treat analysis.

\section{Trial Procedures and Data Collection}

Trial procedure summary, data collection and follow-up are summarized in Table 4. The research paramedics at LAS will collect pre-hospital data from the LAS patient documentation (patient report form, PRF) prior to patient consent. If the patient dies before consent is obtained research paramedics will also collect mortality data. If the patient is delivered to hospital, designated research nurses will collect data for in-hospital stay and the 30-day, 3, 6 and 12-month follow-up time points. All patient information will then be entered online into an electronic case report form provided by www.sealedenvelope.com. Full details of the information collected are provided in the supplementary material. 


\begin{tabular}{|c|c|c|c|c|c|c|c|}
\hline & $\begin{array}{c}\text { Pre- } \\
\text { hospital }\end{array}$ & $\begin{array}{l}\text { On arrival } \\
\text { to hospital }\end{array}$ & In hospital & 30 days & 3 months & 6 months & 12 months \\
\hline Review of eligibility criteria & $\mathrm{x}$ & & & & & & \\
\hline ROSC assessment & $x$ & $\mathrm{x}$ & & & & & \\
\hline Randomization & $x$ & & & & & & \\
\hline Transfer to CAC or hospital & $\mathrm{x}$ & & & & & & \\
\hline $\begin{array}{l}\text { PIS \& Informed consent / } \\
\text { Personal Consultee / } \\
\text { Professional Consultee }\end{array}$ & & & $\mathrm{x}$ & & & & \\
\hline Neurological status & & $x$ & $\mathrm{x}$ & & $\mathrm{x}$ & & \\
\hline Mortality status & & $\mathrm{x}$ & $\mathrm{x}$ & $\mathrm{x}$ & $\mathrm{x}$ & $\mathrm{x}$ & $\mathrm{x}$ \\
\hline EQ-5D-5L & & & $x$ & & & & \\
\hline Service use questionnaire & & & $\mathrm{x}$ & & $\mathrm{x}$ & & \\
\hline SAE / NSAES & $\mathrm{x}$ & $\mathrm{x}$ & $\mathrm{X}$ & $\mathrm{x}$ & $\mathrm{x}$ & & \\
\hline
\end{tabular}

Table 4 Summary of trial procedures and follow up

\section{Outcomes}

The primary outcome is 30-day all-cause mortality. The primary and secondary outcomes are reported in table 5.

Primary Outcome Secondary Outcomes

All-cause mortality at 30 days Neurological status at discharge and 3 months All-cause mortality at 3, 6 and 12 months

EQ-5D-5L at discharge

Table 5: Primary and secondary outcomes 


\section{Statistical Considerations}

Sample size

Mortality at 30 days in the control arm is expected to be approximately $60 \%$ for the cohort of patients recruited into ARREST. This figure is based on Pan London OHCA data ( $87 \%$ mortality with ROSC at any time post cardiac arrest and $73 \%$ mortality with ROSC maintained to hospital), registry data and the pilot randomized trial $(50 \%$ overall mortality). Observational studies on implementation of treatment bundles have shown absolute risk reductions (ARR) of near 30\% compared to the comparator group and in the PROCAT registry an ARR of $16 \%$ was shown following $\mathrm{PCl}$ in post-arrest patients of presumed cardiac cause without STE. ${ }^{12,27,28} \mathrm{~A}$ trial of 860 patients (430 in each arm) will provide $80 \%$ power to detect an absolute reduction of $10 \%$ (i.e. $60 \%$ to $50 \%$ ) including $10 \%$ loss to follow-up and a $5 \%$ significance level. If the mortality is higher than $60 \%$ then the power will increase to detect a $10 \%$ absolute reduction in mortality.

\section{Statistical Analysis}

A detailed statistical analysis plan will be produced prior to any analysis of the data by treatment groups. The primary analysis will be a comparison of all-cause mortality 30 days after randomization between the two arms. A risk difference in all-cause mortality at 30 days together with a $95 \%$ confidence interval and $p$-value will be calculated together with the risk ratio. Similarly, these analyses will be undertaken for all-cause mortality at 3, 6 and 12 months. Kaplan-Meier curves will be produced to show all-cause mortality to 30 days and to 12 months. Hazard ratios will be presented from Cox proportional hazards modelling. Neurological status will also be compared at 3 months using the modified Rankin Score (an ordinal score from 1 (normal neurological status) to 6 (dead) available at www.modifiedrankin.com (Table 6). Ordered logistic regression will be used to compare the two treatments and a trend test computed. Intention-to-treat analysis will be performed as the primary statistical method; this includes all randomized patients in the groups to which they were randomly assigned, regardless of their adherence with the entry criteria, treatment they actually received and deviation from the protocol. Two-sided $p$-values will be used for all superiority testing. All statistical 
analyses shall be performed using Stata ${ }^{\circledR}$ software (Stata Corp. LP). A limited number of pre-planned subgroup analyses on the primary endpoint will be undertaken which will be detailed in the statistical analysis plan. Analyses will be undertaken using logistic regression and a formal test undertaken by including an interaction term between the characteristic and the intervention.

\begin{tabular}{ll} 
Modified Rankin Score & Neurological Outcome \\
\hline 0 & No symptoms \\
1 & No significant disability. Able to carry out all usual activities, despite some symptoms \\
2 & $\begin{array}{l}\text { Slight disability. Able to look after own affairs without assistance but unable to carry out all previous } \\
\text { activities }\end{array}$ \\
3 & Moderate disability. Requires some help but able to walk unassisted \\
4 & Moderately severe disability. Unable to attend to own bodily needs without assistance and/or unable to \\
5 & walk unassisted \\
6 & Severe disability. Requires constant nursing care and attention, bedridden, incontinent \\
\hline
\end{tabular}

Table 6. The modified Rankin Score and the associated neurological outcome (www.modifiedrankin.com)

\section{Health economic evaluation}

This will compare the relative cost and cost-effectiveness of intervention arm to the control arm. Primary economic evaluation will be a cost effectiveness analysis (CEA) based on all-cause mortality at 30 days. The secondary economic evaluation will be a cost utility analysis (CUA) based on Quality Adjusted Life Years (QALYs) derived from health utility data collected using the EQ-5D-5L conducted on 3-month follow-up data. This will take a primarily health and social care perspective. ${ }^{29}$ Service use data, collected using an adapted Client Service Receipt Inventory (CSRI) will comprise 1) hospital admission - including days in intensive care and coronary care 2) procedural cost (laboratory tests, reperfusion therapies, device implantation 3) rehabilitation costs including contact with community professionals, informal care and sick days due to illness. Service use measured will be combined with 
nationally applicable unit costs to derive total costs. 30,31 Intervention costs will be estimated using micro-costing of all resources used for both the intervention and control, using a non-parametric bootstrap regression model to account for non-normal distribution of cost data. ${ }^{32}$ Cost-effectiveness plane (CEP) and cost-effectiveness acceptability curves (CEAC) will be generated. For the CEP, a joint distribution of incremental mean costs and effects for the two strategies will be generated using nonparametric bootstrapping, and plotted against each other. This then shows the probability that the intervention arm has 1) higher costs and better outcomes, 2) higher costs and worse outcomes, 3) lower costs and worse outcomes, or 4) lower costs and better outcomes than control. CEACs are used to explore the probability that each of the treatments is the optimal choice, subject to a range of possible maximum values (ceiling ratio) that a decision-maker might be willing to pay for an additional QALY gained. ${ }^{33}$

\section{Limitations}

Bias

The major sources of bias in this study are differential loss to follow up, lack of blinding and subsequent assessment of outcome. In order to reduce the impact of these potential biases, patients in the two arms will be treated as equally as possible, including consent process and follow up. A further limitation and potential source of bias could arise from the inpatient care following the delivery of a control arm to the nearest ED in a CAC, which is possible in 4 of the 7 CACs in London. This will be addressed by ensuring the control arm receive the care they would normally receive. We do not anticipate bias to affect primary outcome of all-cause mortality.

\section{Control arm crossover to intervention}

Crossover is defined as a patient receiving a pre-hospital care pathway different to the treatment allocation. This likelihood is reduced post-ROSC in the absence of STE on the ECG. A $10 \%$ crossover and loss to follow up has been incorporated into the sample size calculation. If a clinical decision is made either by the in-hospital care team that the patient in the control arm (nearest ED) should receive urgent coronary angiography, this will not be treated as crossover, and is clarified in the control arm 
group. Extensive paramedic training will be in place to prevent contamination of the control group pathway. If patients in the control arm are delivered to an emergency department in a CAC (nearest hospital) we anticipate their pre-hospital course to be less time-sensitive thus affecting post-arrest care.

\section{Potential Risks and Early Stopping}

The potential risk is that of patients with a non-cardiac cause of arrest who are exposed to the intervention. This risk will be minimied by exclusion of obvious non-cardiac cause during eligibility assessment. One patient in the pilot was found to have a non-cardiac cause of arrest and this patient did not survive to hospital. ${ }^{23} 30$-day all-cause mortality will enable identification of such risk with Data Monitoring Committee (DMC) interim analysis. A fully independent DMC has been established to monitor the safety of patients in the trial and a detailed Data Monitoring Charter has been developed. The sample size will not be adjusted to account for interim analyses; however stringent guidelines will be used for the stopping criteria for a benefit of the intervention. ${ }^{7}$ The trial will be terminated if there is substantial evidence of a benefit of the intervention or clear evidence of an increased mortality risk compared to control. The DMC will also monitor recruitment and make recommendations if the recruitment target becomes unlikely in the projected recruitment phase. If the required number of patients is completed in advance of estimated recruitment time then the trial may be completed ahead of schedule depending on the event rates observed. Alternatively, if resources are available recruitment may continue in order to maximise the power of the trial.

\section{Discussion}

There are no randomized controlled trial data demonstrating that time critical delivery to a CAC for definitive care improves survival. Survival following OHCA remains extremely poor and the management of patients without STE is controversial. There is an urgent need for randomized data examining the benefits of urgent delivery of post-cardiac arrest care in specialist centers, specifically in the absence of STE. Post-arrest care is time-critical, requires a multi-disciplinary approach and may be more optimally delivered in centers with greater provider experience. This trial would help demonstrate if regionalization of post-arrest care to specialist centers reduces mortality in patients without STE thus 
has the potential to dramatically reshape emergency care provision. Therefore, either supporting or refuting the current drive, in the lack of randomized data, to immediately transport all post-arrest patients with presumed cardiac cause to a CAC. Outside of the UK, there are now five trials planned or open to recruitment examining the safety, feasibility and timing specifically of reperfusion therapy (immediate coronary angiography \pm percutaneous intervention in post-ROSC patients without STE (Table 7). This trial does not conflict with these because we aim to examine time-critical delivery to a specialist center for urgent evaluation, and definitive treatment that includes but is not limited to immediate access to reperfusion if necessary.

\begin{tabular}{|c|c|c|c|c|c|c|c|c|c|}
\hline Trial Name & $\begin{array}{l}\text { Chief } \\
\text { Investigator }\end{array}$ & Condition & $\begin{array}{l}\text { Primary } \\
\text { Research } \\
\text { Question }\end{array}$ & Intervention & $\begin{array}{l}\text { Treatment } \\
\text { Arm }\end{array}$ & $\begin{array}{l}\text { Control } \\
\text { Arm }\end{array}$ & $\begin{array}{l}\text { Primary } \\
\text { Endpoint }\end{array}$ & $\begin{array}{l}\text { Sample } \\
\text { size }\end{array}$ & $\begin{array}{l}\text { Recruitmen } \\
\text { status }\end{array}$ \\
\hline $\begin{array}{l}\text { Coronariography } \\
\text { in Put of } \\
\text { hosPital Cardiac } \\
\text { arrEst (COUPE); } \\
\text { NCT } 02641626\end{array}$ & $\begin{array}{l}\text { Ana Viana } \\
\text { Tejedor, } \\
\text { Hospital } \\
\text { Clinico San } \\
\text { Carlos, } \\
\text { Spain }\end{array}$ & $\begin{array}{l}\text { Post- } \\
\text { ROSC } \\
\text { cardiac } \\
\text { arrest, no } \\
\text { ST } \\
\text { elevation } \\
\text { on ECG }\end{array}$ & $\begin{array}{l}\text { RCT to } \\
\text { evaluate } \\
\text { the } \\
\text { efficacy of } \\
\text { urgent } \\
\text { versus } \\
\text { deferred } \\
\text { CAG }\end{array}$ & CAG & $\begin{array}{l}\text { Urgent } \\
\text { CAG }\end{array}$ & $\begin{array}{l}\text { Deferred } \\
\text { CAG post } \\
\text { extubation } \\
\text { with CPC } \\
1 \text { or } 2\end{array}$ & $\begin{array}{l}\text { Survival with } \\
\text { CPC } 1 / 2: 30 \\
\text { days and } 6 \\
\text { months } \\
\text { MACE at } 30 \\
\text { days and } 6 \\
\text { months }\end{array}$ & 166 & $\begin{array}{l}\text { Not open to } \\
\text { recruitment }\end{array}$ \\
\hline $\begin{array}{l}\text { Direct or } \\
\text { Subacute } \\
\text { Coronary } \\
\text { Angiography for } \\
\text { Out-of-hospital } \\
\text { Cardiac Arrest } \\
\text { (DISCO); } \\
\text { NCT02309151 }\end{array}$ & $\begin{array}{l}\text { Sten } \\
\text { Rubertsson, } \\
\text { Uppsala } \\
\text { University } \\
\text { hospital; Leif } \\
\text { Svensson, } \\
\text { Stockholm } \\
\text { South } \\
\text { General } \\
\text { hospital, } \\
\text { Sweden }\end{array}$ & $\begin{array}{l}\text { Post- } \\
\text { ROSC } \\
\text { cardiac } \\
\text { arrest, no } \\
\text { ST } \\
\text { elevation } \\
\text { on ECG }\end{array}$ & $\begin{array}{l}\text { RCT to } \\
\text { evaluate } \\
\text { the safety } \\
\text { of urgent } \\
\text { (<120mins) } \\
\text { CAG }\end{array}$ & CAG & $\begin{array}{l}\text { Urgent } \\
C A G<120 \\
\text { mins }\end{array}$ & $\begin{array}{l}\text { CAG } \\
\text { avoided } \\
\text { within the } \\
\text { first } 3 \\
\text { days }\end{array}$ & $\begin{array}{l}\text { Care } \\
\text { deviations } \\
\text { affecting } \\
\text { safety; Pre- } \\
\text { hospital } \\
\text { timeframes; } \\
\text { Logistical } \\
\text { randomisation } \\
\text { problems; } \\
\text { Circulatory } \\
\text { assessment }\end{array}$ & 120 & $\begin{array}{l}\text { Currently } \\
\text { recruiting }\end{array}$ \\
\hline $\begin{array}{l}\text { Cardiac } \\
\text { Catheterisation } \\
\text { in Cardiac } \\
\text { Arrest; NCT } \\
02587494\end{array}$ & $\begin{array}{l}\text { Shahar Lavi, } \\
\text { London } \\
\text { Health } \\
\text { Sciences } \\
\text { Centre, } \\
\text { Ontario, } \\
\text { Canada }\end{array}$ & $\begin{array}{l}\text { Post- } \\
\text { ROSC } \\
\text { cardiac } \\
\text { arrest, no } \\
\text { ST } \\
\text { elevation } \\
\text { on ECG, } \\
\text { VT/NF }\end{array}$ & $\begin{array}{l}\text { Pilot: to } \\
\text { evaluate } \\
\text { the } \\
\text { efficacy of } \\
\text { early } \\
\text { versus late } \\
\text { (or no) } \\
\text { CAG }\end{array}$ & CAG & $\begin{array}{l}\text { Early CAG } \\
(<12 \\
\text { hours })\end{array}$ & $\begin{array}{l}\text { Late or no } \\
\text { CAG (>24 } \\
\text { hours) }\end{array}$ & $\begin{array}{l}\text { Composite of } \\
\text { death and } \\
\text { CPC 3-5 }\end{array}$ & 75 & $\begin{array}{l}\text { Not open to } \\
\text { recruitment }\end{array}$ \\
\hline $\begin{array}{l}\text { Early Coronary } \\
\text { Angiography } \\
\text { Versus Delayed } \\
\text { Coronary } \\
\text { Angiography } \\
\text { (PEARL); } \\
\text { NCT02387398 }\end{array}$ & $\begin{array}{l}\text { Karl Kern, } \\
\text { University of } \\
\text { Arizona, } \\
\text { USA }\end{array}$ & $\begin{array}{l}\text { Post- } \\
\text { ROSC } \\
\text { cardiac } \\
\text { arrest, no } \\
\text { ST } \\
\text { elevation } \\
\text { on ECG }\end{array}$ & $\begin{array}{l}\text { Pilot RCT: } \\
\text { to evaluate } \\
\text { the safety } \\
\text { and } \\
\text { efficacy of } \\
\text { early } \\
\text { versus late } \\
\text { CAG }\end{array}$ & CAG & $\begin{array}{l}\text { Early CAG } \\
<120 \text { mins } \\
\text { from ED } \\
\text { admission }\end{array}$ & $\begin{array}{l}\text { Late or no } \\
\text { CAG (>6 } \\
\text { hours) }\end{array}$ & $\begin{array}{l}\text { Safety } \\
\text { (MACE) and } \\
\text { efficacy of } \\
\text { CAG at } \\
\text { 180days }\end{array}$ & 240 & $\begin{array}{l}\text { Currently } \\
\text { recruiting }\end{array}$ \\
\hline $\begin{array}{l}\text { EMERGEncy } \\
\text { versus delayed } \\
\text { coronary } \\
\text { angiogram in } \\
\text { survivors of out- } \\
\text { of-hospital } \\
\text { cardiac arrest } \\
\text { with no obvious } \\
\text { non cardiac } \\
\text { cause of arrest } \\
\text { (EMERGE); NCT }\end{array}$ & $\begin{array}{l}\text { Christian } \\
\text { Spaulding, } \\
\text { Hôpital } \\
\text { Européen } \\
\text { Georges } \\
\text { Pompidou, } \\
\text { Paris, } \\
\text { France }\end{array}$ & $\begin{array}{l}\text { Post- } \\
\text { ROSC } \\
\text { cardiac } \\
\text { arrest, no } \\
\text { ST } \\
\text { elevation } \\
\text { on ECG, } \\
\text { on } \\
\text { obvious } \\
\text { non- } \\
\text { cardiac } \\
\text { cause }\end{array}$ & $\begin{array}{l}\text { RCT to } \\
\text { evaluate } \\
\text { the } \\
\text { superiority } \\
\text { of early } \\
\text { versus } \\
\text { delayed } \\
\text { CAG }\end{array}$ & CAG & $\begin{array}{l}\text { Urgent } \\
\text { CAG }\end{array}$ & $\begin{array}{l}\text { Delayed } \\
\text { CAG (48- } \\
72 \text { hours) }\end{array}$ & $\begin{array}{l}180 \text { day } \\
\text { survival with } \\
\text { CPC } 1 \text { or } 2\end{array}$ & 970 & $\begin{array}{l}\text { Currently } \\
\text { recruiting }\end{array}$ \\
\hline
\end{tabular}

Table 7 Trials currently recruiting or planning to open to recruitment examining the role of early versus delayed coronary angiography in cardiac arrest survivors without STE. 


\section{References:}

1. Perkins GD, Lockey AS, de Belder MA, et al. National initiatives to improve outcomes from outof-hospital cardiac arrest in England. Emerg Med J. 2016;33(7):448-451. doi:10.1136/emermed2015-204847.

2. Writing Group Members, Mozaffarian D, Benjamin EJ, et al. Heart Disease and Stroke Statistics-2016 Update: A Report From the American Heart Association. Circulation. 2016;133(4):e38-e360. doi:10.1161/CIR.0000000000000350.

3. Sasson C, Rogers MAMM, Dahl J, Kellermann AL. Predictors of Survival From Out-of-Hospital Cardiac Arrest: A Systematic Review and Meta-Analysis. Circ Cardiovasc Qual Outcomes. 2009;3(1):63-81. doi:10.1161/CIRCOUTCOMES.109.889576.

4. Bobrow BJ, Spaite DW, Berg RA, et al. Chest compression-only CPR by lay rescuers and survival from out-of-hospital cardiac arrest. JAMA : the journal of the American Medical Association. 2010;304(13):1447-1454. doi:10.1001/jama.2010.1392.

5. Lick CJ, Aufderheide TP, Niskanen RA, et al. Take Heart America: A comprehensive, community-wide, systems-based approach to the treatment of cardiac arrest. Critical care medicine. 2011;39(1):26-33. doi:10.1097/CCM.0b013e3181fa7ce4.

6. Lurie KG, Idris A, Holcomb JB. Level 1 cardiac arrest centers: learning from the trauma surgeons. Academic emergency medicine : official journal of the Society for Academic Emergency Medicine. 2005;12(1):79-80. doi:10.1197/j.aem.2004.11.010.

7. Nolan JP, Lyon RM, Sasson C, et al. Advances in the hospital management of patients following an out of hospital cardiac arrest. Heart (British Cardiac Society). 2012;98(16):12011206. doi:10.1136/heartjnl-2011-301293.

8. Kern KB. Cardiac receiving centers: beyond hypothermia. Current opinion in critical care. 2012;18(3):246-250. doi:10.1097/MCC.0b013e32835180d6.

9. Jacobs AK. Regional systems of care for patients with ST-elevation myocardial infarction: being at the right place at the right time. Circulation. 2007;116(7):689-692.

doi:10.1161/CIRCULATIONAHA.107.720946.

10. Acker JE, Pancioli AM, Crocco TJ, et al. Implementation strategies for emergency medical services within stroke systems of care: a policy statement from the American Heart Association/American Stroke Association Expert Panel on Emergency Medical Services Systems and the Stroke Council. Stroke. 2007;38(11):3097-3115. doi:10.1161/STROKEAHA.107.186094.

11. Cameron PA, Gabbe BJ, Cooper DJ, Walker T, Judson R, McNeil J. A statewide system of trauma care in Victoria: effect on patient survival. Med J Aust. 2008;189(10):546-550.

12. Sunde K, Pytte M, Jacobsen D, et al. Implementation of a standardised treatment protocol for post resuscitation care after out-of-hospital cardiac arrest. Resuscitation. 2007;73(1):29-39. doi:10.1016/j.resuscitation.2006.08.016.

13. Kahn JM, Goss CH, Heagerty PJ, Kramer AA, O'Brien CR, Rubenfeld GD. Hospital volume and the outcomes of mechanical ventilation. The New England journal of medicine. 2006;355(1):4150. doi:10.1056/NEJMsa053993. 
14. Kern KB. Optimal treatment of patients surviving out-of-hospital cardiac arrest. JACC: Cardiovascular Interventions. 2012;5(6):597-605. doi:10.1016/j.jcin.2012.01.017.

15. Peberdy MA, Donnino MW, Callaway CW, et al. Impact of Percutaneous Coronary Intervention Performance Reporting on Cardiac Resuscitation Centers: A Scientific Statement From the American Heart Association. Circulation. July 2013. doi:10.1161/CIR.0b013e3182a15cd2.

16. Peberdy MA, Callaway CW, Neumar RW, et al. Part 9: post-cardiac arrest care: 2010 American Heart Association Guidelines for Cardiopulmonary Resuscitation and Emergency Cardiovascular Care. Circulation. 2010;122(18 Suppl 3):S768-S786. doi:10.1161/CIRCULATIONAHA.110.971002.

17. Neumar RW, Nolan JP, Adrie C, et al. Post-cardiac arrest syndrome: epidemiology, pathophysiology, treatment, and prognostication. A consensus statement from the International Liaison Committee on Resuscitation (American Heart Association, Australian and New Zealand Council on Resuscitation. Circulation. 2008;118(23):2452-2483. doi:10.1161/CIRCULATIONAHA.108.190652.

18. Noc M, Fajadet J, Lassen JF, et al. Invasive coronary treatment strategies for out-of-hospital cardiac arrest: a consensus statement from the European association for percutaneous cardiovascular interventions (EAPCI)/stent for life (SFL) groups. Eurolntervention : journal of EuroPCR in collaboration with the Working Group on Interventional Cardiology of the European Society of Cardiology. 2014;10(1):31-37. doi:10.4244/EIJV10l1A7.

19. Spaulding CM, Joly LM, Monchi M, et al. Immediate coronary angiography in survivors of out-ofhospital cardiac arrest. The New England journal of medicine. 1997;336(23):1629-1633. doi:10.1056/NEJM199706053362302.

20. Levine GN, Bates ER, Blankenship JC, et al. 2015 ACC/AHA/SCAI Focused Update on Primary Percutaneous Coronary Intervention for Patients With ST-Elevation Myocardial Infarction: An Update of the 2011 ACCF/AHA/SCAI Guideline for Percutaneous Coronary Intervention and the 2013 ACCF/AHA Guideline for the Management of ST-Elevation Myocardial Infarction: A Report of the American College of Cardiology/American Heart Association Task Force on Clinical Practice Guidelines and the Society for Cardiovascular Angiography and Interventions. Circulation. 2015;133(11):CIR.0000000000000336-CIR.00000000000001147. doi:10.1161/CIR.0000000000000336.

21. Ibanez B, James S, Agewall S, et al. 2017 ESC Guidelines for the management of acute myocardial infarction in patients presenting with ST-segment elevation: The Task Force for the management of acute myocardial infarction in patients presenting with ST-segment elevation of the European Society of Cardiology (ESC). European heart journal. August 2017. doi:10.1093/eurheartj/ehx393.

22. Nikolaou NI, Welsford M, Beygui F, et al. Part 5: Acute coronary syndromes: 2015 International Consensus on Cardiopulmonary Resuscitation and Emergency Cardiovascular Care Science with Treatment Recommendations. Resuscitation. 2015;95:e121-e146. doi:10.1016/j.resuscitation.2015.07.043.

23. Patterson T, Perkins GD, Joseph J, et al. A Randomised tRial of Expedited transfer to a cardiac arrest centre for non-ST elevation ventricular fibrillation out-of-hospital cardiac arrest: The ARREST pilot randomised trial. Resuscitation. 2017;0(0):185-191. doi:10.1016/j.resuscitation.2017.01.020.

24. Pattinson SD. Emergency research and the interests of participants. Medical Law International. 2012;12(2):121-141. doi:10.1177/0968533212465615. 
25. GMC. Good Practice in Research and Consent to Research. 2010.

26. Mason S, Barrow H, Phillips A, et al. Brief report on the experience of using proxy consent for incapacitated adults. Journal of medical ethics. 2006;32(1):61-62. doi:10.1136/jme.2005.012302.

27. Dumas F, Cariou A, Manzo-Silberman S, et al. Immediate percutaneous coronary intervention is associated with better survival after out-of-hospital cardiac arrest: insights from the PROCAT (Parisian Region Out of hospital Cardiac ArresT) registry. Circulation: Cardiovascular Interventions. 2010;3(3):200-207. doi:10.1161/CIRCINTERVENTIONS.109.913665.

28. Franzosi MG, Santoro E, De Vita C, et al. Ten-year follow-up of the first megatrial testing thrombolytic therapy in patients with acute myocardial infarction: results of the Gruppo Italiano per lo Studio della Sopravvivenza nell'Infarto-1 study. The GISSI Investigators. Circulation. 1998;98(24):2659-2665. doi:10.1161/01.CIR.98.24.2659.

29. Earnshaw J, Lewis G. NICE guide to the methods of technology appraisal. Pharmacoeconomics. 2008;26(9):725-727.

30. National Health Service Schedule of Reference Costs 2013/2014.

31. Curtis L. Unit Costs of Health and Social Care. Unit Costs of Health and Social Care. 2014.

32. Barber JA, Thompson SG. Analysis of cost data in randomized trials: an application of the nonparametric bootstrap. Stat Med. 2000;19(23):3219-3236.

33. Claxton $\mathrm{K}$. The irrelevance of inference: a decision-making approach to the stochastic evaluation of health care technologies. J Health Econ. 1999;18(3):341-364. 